\title{
Losartan: ¿una alternativa en la Insuficiencia Cardíaca?
}

Meta-Analysis of observed Mortality data from All-Controlled, Double-Blind, Multiple-Dose Studies of Losartan in Heart Failure. Sharma D, Buyse M, Pitt B, and Rucinska EJ, and the Losartan Heart Failure Mortality Meta-analysis Study Group. American J Cardiol 2000;85:187-192.

\section{Objetivo}

Evaluar la mortalidad por todas las causas en pacientes con Insuficiencia Cardíaca (IC) tratados con losartan.

\section{Fuente de Datos y Selección de Estudios}

Se seleccionaron los 8 ensayos clínicos controlados, aleatorizados (ECCA), doble ciego, de dosis múltiple $(2,5-50 \mathrm{mg})$ de losartan en IC, disponibles en la literatura. Dos estudios (uno sobre farmacocinética y otro de dosis única), durante los que no hubo muertes, no calificaron para su inclusión en el meta-análisis. Los 6 incluidos pueden verse en la tabla.

\section{Extracción de datos}

Todos los pacientes aleatorizados fueron analizados por intención de tratar durante el período doble ciego, independientemente de las causas de abandono o apartamientos del protocolo.

Resultados Principales

Se enrolaron 1894 pacientes: 1154 aleatorizados al Grupo Losartan (GL) y 740 al de tratamiento de control (GC) (274 placebo, 96 enalapril y 370 captopril). Hubo más hombres que mujeres en todos los estudios y eran principalmente de raza blanca. La edad media fue apro- ximadamente 60 años, excepto en el ELITE que eran > 70 años. El diagnóstico de IC se hizo, en su mayoría, dentro de los últimos 5 años y la etiología fue cardiopatía isquémica en más de la mitad de los pacientes. La Fracción de Eyección media reportada en cada estudio osciló entre 23 y $31 \%$. No hubo diferencias significativas entre los grupos de tratamiento en ninguna de las características demográficas o de la IC. El uso de inhibidores de la enzima convertidora de angiotensina (IE(A) en forma abierta no se permitió en ningún estudio. Durante el seguimiento medio de 25,4 semanas hubo 47 muertes en el GC $(6,35 \%)$ vs $36(3,12 \%)$ en el GL (OR 0,5 IC95\% 0,32-0,81; $p=0,004)$. La descripción y resultados de cada estudio figuran en la tabla.

Analizándolos por grupos, el OR para estudios controlados contra placebo fue 0,34 (IC95\% 0,14-0,8) y contra IECA 0,6 (IC95\% 0,34-1,04). El OR en estudios de pacientes que nunca recibieron IECA fue 0,44 (IC95\% $0,26-0,76)$ y en aquellos que recibieron IECA 0,76 (IC95\% 0,3-1,96).

\section{Conclusiones}

El tratamiento con Losartan mejora la sobrevida de los pacientes con IC pero dado el escaso seguimiento y No de muertes será necesario un gran estudio confirmatorio que evalúe este beneficio comparado con IECA.

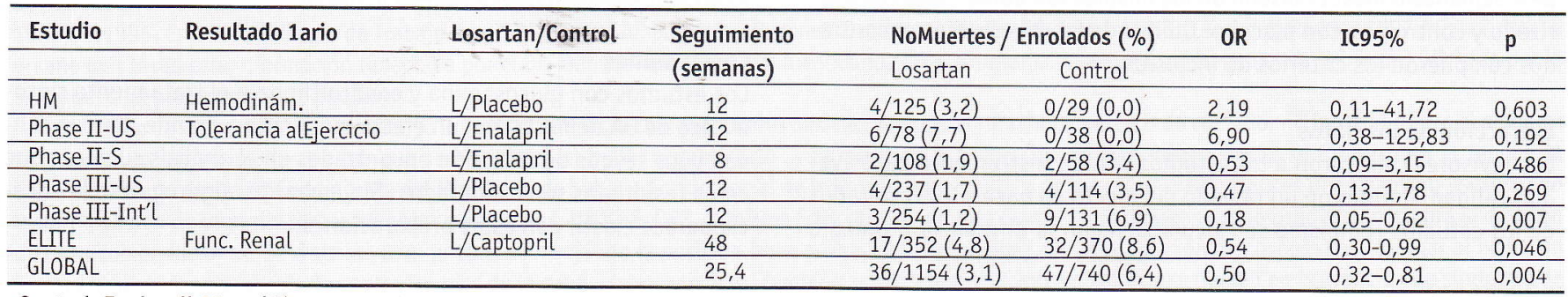

Control: Enalapril 20mg/día, Captopril 18,75Æ150mg/día

Fuente de financiamiento: Merck Research Laboratories.

\section{COMENTARIO}

El Losartan es un Antagonista de los Receptores de Angiotensina II (ARA-II). A diferencia de los IECA, no aumentan la bradiquinina, que es responsable de algunos efectos adversos como la tos pero también de efectos benéficos como vasodilatación y mejoría del flujo regional. ${ }^{1}$ La AII de los vasos miocárdicos se produciría por una vía independiente de la ECA, por lo que los ARA-II tendrían ventajas potenciales sobre los IECA. ${ }^{2}$ En pacientes con IC el Losartan tuvo buena tolerancia y se asoció con mejoría hemodinámica y sintomática. ${ }^{3-4}$ En el mayor estudio sobre ARA-II (ELITE) 5 se observó en los ancianos con IC una inesperada reducción de la mortalidad comparada con captopril, pero este estudio de seguridad no estaba diseñado para valorar mortalidad y el hallazgo pudo deberse al azar. Sin embargo también se observó un beneficio similar al combinar el resto de los estudios considerados en el meta-análisis. A pesar de la consistencia de resultados, en estos últimos pequeños ECCA de corto seguimiento (media de 11,4 semanas) hubo pocas muertes observadas y ciertas evidencias de heterogeneidad, siendo indispensable grandes estudios confirmatorios específicamente diseñados para valorar mortalidad comparado con IECA (en marcha el ELITE II [losartan], VALHEFT [valsartan] y CHARM [candesartan]). Es destacable que aunque en 3 de los 6 estudios el GC recibió IECA como droga activa, aún así pudo hallarse un beneficio en la sobrevida. De esta forma el beneficio en mortalidad no deja de ser una estimación conservadora. Además las tasas de mortalidad del GL (1,8 a 4,6\% en seguimientos de 2-11 meses) fue menores que en meta-análisis previos de IECA aún después de excluir los estudios de largo plazo (mortalidad de 5,76 y $6,4 \% 7$ en seguimientos de 3-6 meses). Si, por ejemplo, la tos fuera la causa de la suspensión de los IECA, sería aconsejable probar con losartan antes de reemplazarlos por dinitrato de isosorbide + hidralazina. La dosis inicial de losartan es de $12.5-25 \mathrm{mg} /$ día y el objetivo de dosis (máxima) se alcanzan con $50 \mathrm{mg} /$ día.

Si bien deberá aguardarse a que los estudios en marcha confirmen o descarten los eventuales beneficios de sobrevida de los ARA-II por sobre los IECA, puede afirmarse que los ARA-II (aunque los autores prefieran no asumir efecto de clase del Losartan por particularidades de esta droga) constituyen una segura alternativa en caso de intolerancia a IECA.

\section{Dr. Agustín Ciapponi}

Unidad de Medicina Familiar y Preventiva. Hospital Italiano de Buenos Aires

\section{Referencias}

1. Linz W, Wiemer G, Gohlke P, et al. Contribution of kinins to the cardiovascular actions of angiotensin-converting enzyme inhibitors Pharmacol Rev 1995:47:25-49.

2. Urata H, Kinoshita A, Misono KS, et al. Identification of a highly specific chymasa as the major angiotensin II-forming enzyme in the human chymasa. J Bilo Chem $1990 ; 256: 22348-22357$. 3. Crozier I, Ikram H, Awan N, et al. Losartan in Heart Failure. Hemodynamic effect and tolerability. Circulation 1995;91:691-7.

4. Sweet CS, Rucinska EJ. Losartan in Heart Failure: preclinical experiences and initial clinical outcomes. Europ Heart 1994;15(suppl. D):139-144.

5. Pitt B, Segal R, Martinez FA, et al. Randomised trial of Losartan vs captopril in patients over 65 with heart failure (Evaluation of Losartan in the Eldery Study, ELTE). Lancet 1997: $349: 747-52$ 6. Garg R, Yusuf S. Overview of randomized trials of angiotensin-converting enzyme inhibitors on the mortality and morbidity in patients with heart failure. JAMA 1995;18:1450-55.

7. Nony P, Boissel JP, Girard p, et al. Relative efficacy of angiotensin-converting enzyme inhibitors on mortality of patients with heart failure: implications of randomized trials and role of the aetiology (ichaemic and non- ichaemic) of heart failure. European Heart 1992;13:1101-1108. 